\title{
Papillary Thyroid Cancer in Struma Testis with Malignant Transformation in the Lung Associated with Trisomy 17 Successfully Treated with Total Thyroidectomy and Radioiodine Ablation
}

\author{
Shadi Barakat ${ }^{a} \quad$ Jamie Odem $^{\mathrm{b}} \quad$ Jacqueline R. Batanian ${ }^{\mathrm{e}, \mathrm{f}} \quad$ Shahzad Raza $^{\mathrm{c}}$ \\ Uzma Z. Khan ${ }^{\text {d }}$ \\ ${ }^{a}$ Department of Endocrinology, St. Agnes Hospital, Baltimore, Md., Departments of \\ ${ }^{b}$ Pathology, ${ }^{C}$ Hematology and Oncology and ${ }^{d}$ Endocrinology, University of Missouri- \\ Columbia, Columbia, Mo., and Departments of ${ }^{\mathrm{e}}$ Pediatrics and ${ }^{\mathrm{f}}$ Pathology, Saint Louis \\ University, Medical Center, Saint Louis, Mo., USA
}

\section{Key Words}

Trisomy $17 \cdot$ Struma testis $\cdot$ Papillary thyroid cancer $\cdot$ Comparative genomic hybridization

\begin{abstract}
Background: Struma testis is a rare entity, and there are only few reports on the malignant transformation of a testicular teratoma to papillary thyroid carcinoma in the literature. In this report, we describe the malignant transformation of struma testis with distant lung metastasis associated with trisomy 17 and a coexisting papillary microcarcinoma in the thyroid. Case Report: A 56-year-old man presented after a left orchiectomy for an undescended left testicle. Pathologic examination identified a monodermal teratoma composed of thyroid parenchyma and associated with a $1.7-\mathrm{cm}$ papillary thyroid carcinoma. Further evaluation showed a pulmonary mass on a chest CT scan. Total thyroidectomy revealed a $0.5-\mathrm{mm}$ focus of papillary thyroid cancer, and removal of the lung mass confirmed metastatic papillary thyroid cancer. Array-comparative genomic hybridization of both tumors showed trisomy 17 in the struma testes and the lung metastasis. The patient responded well to radioactive iodine ablation and has no evidence of cancer 3 years later. Conclusion: To our
\end{abstract}


Barakat et al.: Papillary Thyroid Cancer in Struma Testis with Malignant Transformation in the Lung Associated with Trisomy 17

knowledge, this is the first case of papillary thyroid cancer in struma testes metastatic to the lung. It highlights the difficulties in treating these patients. Surgery to remove cancer foci, followed by radioactive iodine ablation, resulted in an excellent response in our patient. Interestingly, trisomy 17 , which has so far been observed only in noninvasive thyroid nodules, was associated with pulmonary metastasis in our patient.

(c) 2014 S. Karger AG, Basel

\section{Introduction}

Papillary thyroid carcinoma is the most common type of differentiated thyroid carcinoma, which is usually confined to the thyroid and tends to metastasize to regional lymph nodes [1]. Cases identifying thyroid tissue in an ovarian teratoma and struma ovarii are well described in the literature. It is estimated that thyroid tissue presents in $15 \%$ of ovarian teratomas and that it is the dominant tissue, classified as struma ovarii, in $5 \%$ of the cases $[1$, 2]. Only $2-10 \%$ of struma ovarii cases show malignant transformation $[3,4]$. However, struma testis is an extremely rare variant of testicular teratoma. Here, we describe a rare case of struma testis characterized by malignant transformation and pulmonary metastasis associated with trisomy 17 , with a coexisting papillary microcarcinoma of the thyroid.

\section{Case Report}

A 56-year-old Caucasian male with a history of an undescended left testicle was admitted to a community hospital with right lower quadrant pain. The clinical and radiological evaluations were consistent with appendicitis. Although he had refused orchiectomy in the past, he consented to it on this admission. He underwent laparoscopic appendectomy and left orchiectomy. The left testicle was noted to be in the left pelvic sidewall and was resected without complication. Prior to admission, he was asymptomatic and denied weight loss, dysphagia, odynophagia, and voice hoarseness. He did not have a history of smoking, exposure to radiation, or a family history of thyroid cancer.

The evaluation for testicular tumor markers included normal serum $\alpha$-fetoprotein and normal serum $\beta$-human chorionic gonadotropin. Lactate dehydrogenase was slightly elevated (680 units/l, normal range 313-618). A chest X-ray on the day of admission revealed a well-demarcated $3-\mathrm{cm}$ round density in the lower right perihilar region. A CT scan of the chest with intravenous contrast showed a well-circumscribed soft tissue mass arising from the inferior right hilar area, with a size of $2.2 \times 2.4 \times 2.7 \mathrm{~cm}$, as well as a $0.7-\mathrm{cm}$ lesion in the right superior hilar area and multiple smaller nodules in the lower lobes of both lungs.

The pathology report identified the testicular tissue as a monodermal teratoma composed of thyroid parenchyma and associated with the development of papillary thyroid carcinoma with a predominantly follicular growth pattern (fig. 1). Immunoperoxidase stains demonstrated that the neoplastic cells were strongly positive for cytokeratin CAM 5.2 and thyroid transcription factor 1 . $\alpha$-Fetoprotein, vimentin, $\beta$-human chorionic gonadotropin, placental alkaline phosphatase, S100, CD30, inhibin, and calretinin stains were negative in the malignant cells.

A video-assisted thoracoscopic wedge biopsy of the right lower lobe nodule revealed metastatic papillary thyroid carcinoma. Due to concerns about the effectiveness of I-131 ablation in the presence of a right lower lobe mass, the decision was made to perform open right lower lobectomy. A wedge resection of the right upper lobe nodule was also performed. 
Barakat et al.: Papillary Thyroid Cancer in Struma Testis with Malignant Transformation in the Lung Associated with Trisomy 17

The pathology report of all specimens confirmed papillary thyroid cancer, with a maximum tumor size of $2.1 \mathrm{~cm}$ in the right lower lung lobe (fig. 2).

In preparation for treatment with radioactive iodine, total thyroidectomy was performed. Interestingly, the patient had one microscopic focus $(0.5 \mathrm{~mm})$ of papillary carcinoma with follicular architecture (fig. 3). A pretreatment stimulated (thyroid-stimulating hormone $95 \mathrm{mIU} / \mathrm{ml}$ ) whole-body scan using $1.5 \mathrm{mCi}$ of I-123 showed a residual uptake in the neck $(2.5 \%)$ in addition to foci of increased uptake in the lungs bilaterally. At the same time, the serum thyroglobulin ( $\mathrm{Tg}$ ) level was $16.8 \mathrm{ng} / \mathrm{ml}$, and that of $\mathrm{Tg}$ antibodies (TgAbs) $<0.9$ $\mathrm{IU} / \mathrm{ml}$.

To determine whether the papillary microcarcinomas of the lung and testis have a similar origin, we performed BRAF and RAS (HRAS, NRAS, and KRAS) mutational analyses, which were negative, and comparative genomic hybridization (array-comparative genomic hybridization, a-CGH) from both the lung and testis revealed trisomy 17 and monosomy $\mathrm{X}$, indicating their common origin (fig. 4).

The patient was treated with $200 \mathrm{mCi}$ of I-131, and the posttherapy whole-body scan did not show any new areas of increased uptake. He was started on levothyroxine $175 \mu \mathrm{g}$ daily and did very well clinically and biochemically. Nonstimulated (thyroid-stimulating hormone $0.111 \mathrm{mIU} / \mathrm{ml}$ ) Tg and TgAbs were undetectable. One year after the I-131 ablation, thyrogen-stimulated Tg was $<0.2 \mathrm{ng} / \mathrm{ml}$, with TgAbs at $<20 \mathrm{IU} / \mathrm{ml}$ (normal range 0.00-20), and a whole-body scan using $1.55 \mathrm{mCi}$ of I-123 did not show any iodine concentration areas consistent with metastases. A CT scan of the neck and chest revealed a decrease in the size of the unresected lung nodules. Three years after treatment, he continues to have undetectable Tg levels.

\section{Discussion}

We presented a unique case of a metastatic papillary thyroid carcinoma from struma testis and raised the question whether the testicular and lung lesions could be metastases from the papillary thyroid microcarcinoma. This is very unlikely for two reasons. First, normal thyroid tissue was present adjacent to the malignant papillary thyroid component in the teratoma, making it most likely that the teratomatous thyroid tissue underwent malignant transformation. Second, it is generally accepted that papillary microcarcinomas exhibit benign behavior and have an overall excellent prognosis [1]. In fact, there is an up to $35 \%$ incidental prevalence of papillary microcarcinoma at autopsy $[5,6]$. Furthermore, distant metastases from papillary microcarcinomas are reported to be $0.6 \%$ in a large metaanalysis [7]. The sites of distant metastasis from papillary microcarcinoma included pulmonary [8], intratracheal [9], and cervical lymph nodes [10]. However, no cases of papillary microcarcinoma metastasizing below the diaphragm in general, and to the testis specifically, have ever been reported. On the contrary, there is a case report of a malignant metastatic testicular teratoma that was found initially in the thyroid [11].

Furthermore, molecular genetic analysis of the three tumors was performed in order to answer the question of whether the papillary microcarcinoma could have been the primary tumor. First, BRAF V600E and RAS (HRAS, NRAS, and KRAS) mutational analyses were performed and were negative. The DNA extracted from the testis and lung separately was hybridized with normal DNA controls onto an a-CGH designed by NimbleGen and analyzed using Genoglyphix software (Perkin Elmer, Signature Genomics, Spokane, Wash., USA). The thyroid microcarcinoma could not be evaluated, because no malignant tissue remained for sampling. The a-CGH revealed similar findings in both the lung and testis. Each tumor had 
Barakat et al.: Papillary Thyroid Cancer in Struma Testis with Malignant Transformation in the Lung Associated with Trisomy 17

trisomy 17 and monosomy X, indicating their common origin. Frau et al. [12] have demonstrated a strong association between isolated trisomy 17 and follicular thyroid nodules, which have nuclear features of papillary thyroid carcinoma, suggesting a link between papillary thyroid carcinoma and trisomy 17 . However, all nine cases studies were noninvasive. In our case, the a-CGH indicates that the testis and lung have the same genomic profile and are therefore most likely of the same origin (i.e. teratomatous transformation in the struma testis which metastasized to the lung). The significance of the monosomy $\mathrm{X}$ is unclear.

There are only few reports in the literature on malignant struma testis. The first case was a 65-year-old male who was found to have a cystic structure in the testes described as viable thyroid tissue with areas of complex papillary arrangements [13]. The second case of malignant struma testis was a 68-year-old euthyroid male with a $5-\mathrm{cm}$ mass in the upper pole of the right testis [14]. Gross and microscopic examination revealed a replacement of testicular parenchyma with a microcystic tumor that had the appearance of normal thyroid tissue with histologically, solid, trabecular, follicular, and papillary areas. Unfortunately, genetic analysis was not performed in these cases.

For the first time, we report a case with struma testis that underwent malignant transformation with distant lung metastasis as confirmed by a-CGH, and without regional paraaortic lymph nodes, and a coexisting papillary microcarcinoma in the thyroid. Our approach to the management of this tumor seems to be rewarding as the patient is cancer free 3 years later. Trisomy 17, which has typically been associated with noninvasive thyroid nodules with features of focal papillary carcinoma changes, was detected in both testicular and pulmonary tissues, confirming the invasive nature of the tumor. a-CGH studies on these rare tumors may further this association.

\section{Conclusion}

In recent years, increasing focus on the cytogenetic and molecular analysis of tumor cells has allowed a better understanding of thyroid nodules as well as of thyroid cancer. Our case provides evidence of a papillary thyroid cancer in struma testes metastatic to the lung, confirmed by CGH studies. The case also highlights the difficulties in treating these patients. Surgery to remove cancer foci, followed by radioactive iodine ablation, resulted in an excellent response in our patient. In contrast to previous studies, our case report has shown that trisomy 17, which has so far been observed only in noninvasive thyroid nodules, was associated with pulmonary metastasis.

\section{Disclosure Statement}

The authors declare that there are no conflicts of interest regarding the publication of this paper. 


\section{Case Reports in Oncology}

\begin{tabular}{l|l}
\hline Case Rep Oncol 2014;7:751-757 \\
\hline DOI: $10.1159 / 000369202$ & $\begin{array}{l}\text { C 2014 S. Karger AG, Basel } \\
\text { www.karger.com/cro }\end{array}$ \\
\hline
\end{tabular}

Barakat et al.: Papillary Thyroid Cancer in Struma Testis with Malignant Transformation in the Lung Associated with Trisomy 17

\section{References}

1 Caron NR, Clark OH: Papillary thyroid cancer. Curr Treat Options Oncol 2006;7:309-319.

-2 Craver BS, Al-Ahmadie H, Sheinfeld J: Adult and pediatric testicular teratoma. Urol Clin North Am 2007;34:245-251.

3 Salman WD, Singh M, Twaij Z: A case of papillary thyroid carcinoma in struma ovarii and review of the literature. Patholog Res Int 2010;2010:352476.

-4 Doganay M, Gungor T, Cavkaytar S, Sirvan L, Mollamahmutoglu L: Malignant struma ovarii with a focus of papillary thyroid cancer: a case report. Arch Gynecol Obstet 2008;277:371-373.

5 Lam AK, Lo CY, Lam KS: Papillary carcinoma of thyroid: a 30-yr clinicopathological review of the histological variants. Endocr Pathol 2005;16:323-330.

6 Chow SM, Law SC, Chan JK, Au SK, Yau S, Lau WH: Papillary microcarcinoma of the thyroid - prognostic significance of lymph node metastasis and multifocality. Cancer 2003;98:31-40.

7 Mazzaferri EL: Management of low-risk differentiated thyroid cancer. Endocr Pract 2007;13:498-512.

8 Strate SM, Lee EL, Childers JH: Occult papillary carcinoma of the thyroid with distant metastases. Cancer 1984;54:1093-1100.

-9 Paksoy N, Oztürk H, Demircan A, Artvinli M: Occult papillary carcinoma of the thyroid presenting as an intratracheal tumor. Eur J Surg Oncol 1994;20:694-695.

10 Monchik JM, De Petris G, De Crea C: Occult papillary carcinoma of the thyroid presenting as a cervical cyst. Surgery 2001;129:429-432.

-11 Gazel P, Hamansi T, El-Hafed A, et al: Les cancers secondaires de la thyroide. J Fr Otorhinolaryngol Audiophonol Chir Maxillofac 1982;31:473-476.

12 Frau DV, Lai ML, Caria P, et al: Trisomy 17 as a marker for a subset of noninvasive thyroid nodules with focal features of papillary carcinoma: cytogenetic and molecular analysis of 62 cases and correlation with histological findings. J Clin Endocrinol Metab 2008;93:177-181.

13 Pal AK, Chopra SK, Kalra AS: Calcifying malignant struma of the testis. A case report. Indian J Cancer 1975;12:210-213.

14 Waxman M, Vuletin JC, Pertschuk LP, Bellamy J, Enu K: Pleomorphic atypical thyroid adenoma arising in struma testis: light microscopic, ultrastructure, and immunofluorescent studies. Mt Sinai J Med 1982;49:1317.

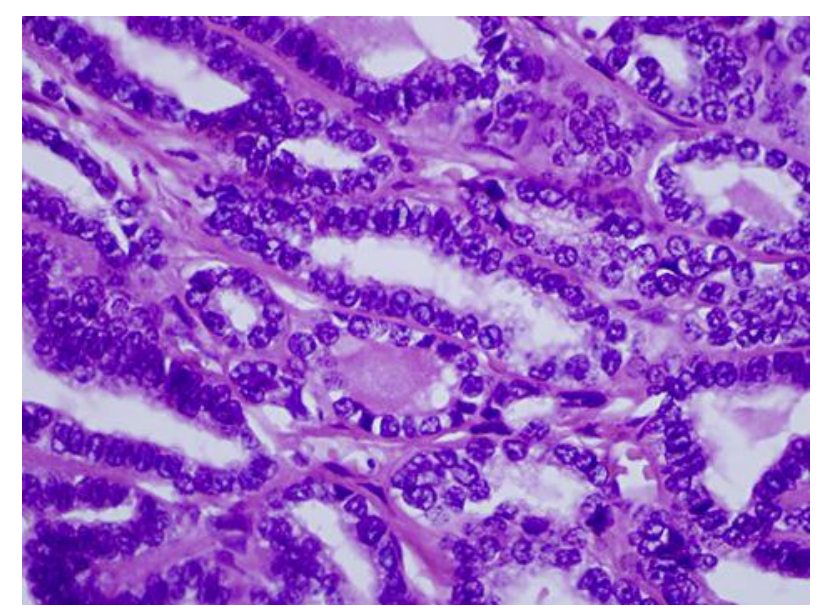

Fig. 1. Higher-power view of papillary thyroid cancer arising from struma testis. The cells are overlapping and enlarged, with prominent nuclear grooves and focal nuclear pseudoinclusions. The architecture here is predominantly follicular. H\&E. $\times 60$. 


\section{Case Reports in Oncology}

\begin{tabular}{l|l}
\hline Case Rep Oncol 2014;7:751-757 \\
\hline DOI: $10.1159 / 000369202$ & $\begin{array}{l}\text { (c) 2014 S. Karger AG, Basel } \\
\text { www.karger.com/cro }\end{array}$ \\
\hline
\end{tabular}

Barakat et al.: Papillary Thyroid Cancer in Struma Testis with Malignant Transformation in the Lung Associated with Trisomy 17

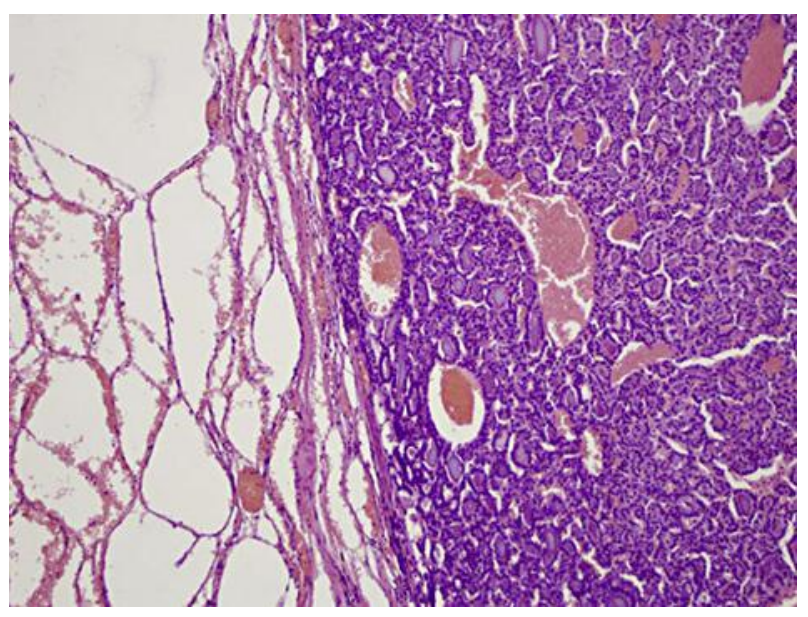

Fig. 2. Papillary thyroid cancer metastasis to the lung with a predominantly follicular pattern. The healthy lung is visible adjacent to the tumor. H\&E. $\times 2$ and $\times 10$.

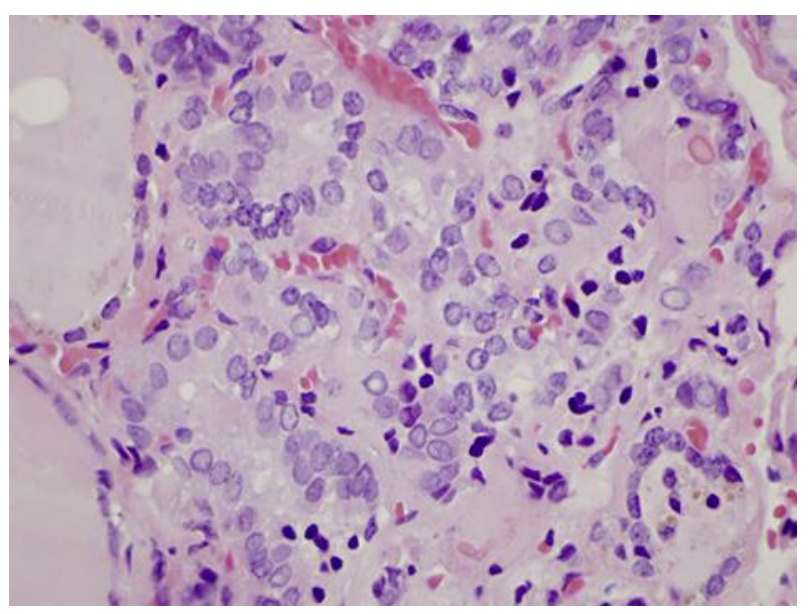

Fig. 3. Papillary microcarcinoma from total thyroidectomy. The microcarcinoma measures $0.5 \mathrm{~mm}$ and has a follicular architecture. H\&E. $\times 40$. 


\section{Case Reports in Oncology}

\begin{tabular}{l|l}
\hline Case Rep Oncol 2014;7:751-757 \\
\hline DOI: 10.1159/000369202 & $\begin{array}{l}\text { C 2014 S. Karger AG, Basel } \\
\text { www.karger.com/cro }\end{array}$ \\
\hline
\end{tabular}

Barakat et al.: Papillary Thyroid Cancer in Struma Testis with Malignant Transformation in the Lung Associated with Trisomy 17

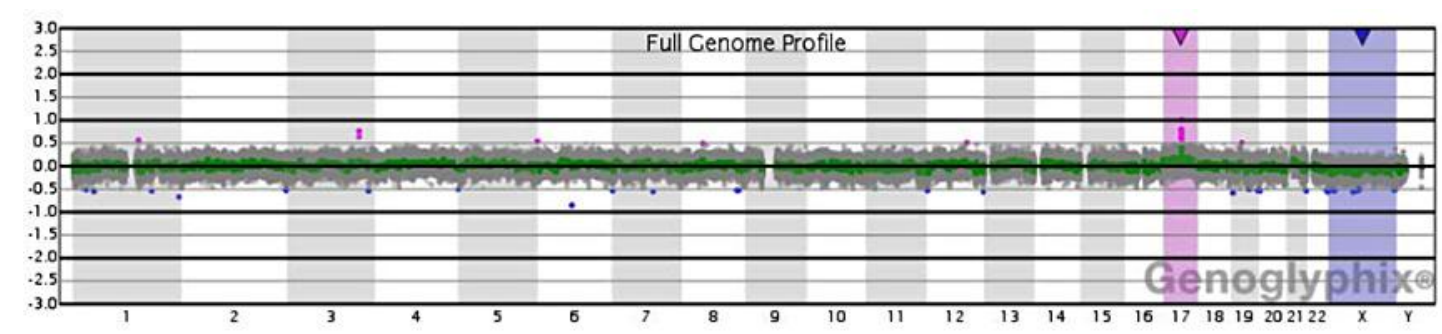

Fig. 4. The a-CGH of both tumors revealed the same full genomic profile. The green line represents the smooth $\log _{2}$ ratio of any difference in the amount of fluorescent signals between the genotype of the tumor and normal tissue. The green line is at 0.0 for all chromosomes $(1,22, \mathrm{X}$ and $\mathrm{Y}$ ) except for chromosome 17 and $\mathrm{X}$, indicating a normal quantity for all chromosomes between the tumor and the normal tissue except for chormosomes 17 and $\mathrm{X}$. The green line is above 0.0 for chromosome 17 , indicating a gain, as also illustrated by the pink probes being far from the standard deviation (gray zone). The Genoglyphix software highlights the gain by a red column. The green line is below 0.0 for chromosome $\mathrm{X}$, indicating a loss, as illustrated by the blue probes being far from the standard deviation (gray zone). The Genoglyphix software highlights the loss by a blue column. 